\title{
BILANGAN RAINBOW CONNECTION UNTUK BEBERAPA GRAF THORN
}

\author{
MELVI MUCHLIAN \\ Program Studi Magister Matematika, \\ Fakultas Matematika dan Ilmu Pengetahuan Alam, Universitas Andalas, \\ Kampus UNAND Limau Manis Padang, Indonesia, \\ email : melvimuchlian@gmail.com
}

\begin{abstract}
Abstrak. Misalkan $G=(V(G), E(G))$ adalah suatu graf terhubung tak trivial. Definisi pewarnaan $c: E(G) \rightarrow\{1,2, \cdots, k\}, k \in N$, dimana dua sisi yang bertetangga boleh berwarna sama. Suatu lintasan $u-v$ path $P$ di $G$ dinamakan rainbow path jika tidak terdapat dua sisi di $P$ yang berwarna sama. Graf $G$ disebut rainbow connected jika setiap dua titik yang berbeda di $G$ dihubungkan oleh rainbow path. Pewarnaaan sisi yang menyebabkan $G$ bersifat rainbow connected dikatakan rainbow coloring. Bilangan Rainbow connection dari graf terhubung $G$, ditulis $r c(G)$, didefinisikan sebagai banyaknya warna minimal yang diperlukan untuk membuat graf $G$ bersifat rainbow connected. Misalkan $c$ adalah rainbow coloring dari graf terhubung $G$. Untuk dua titik $u$ dan $v$ di $G$, rainbow $u-v$ geodesic pada $G$ adalah rainbow $u-v$ path yang panjangnya $d(u, v)$ dimana $d(u, v)$ adalah jarak antara $u$ dan $v$ (panjang $u-v$ path terpendek di $(G)$. Graf $G$ dikatakan strongly rainbow connected jika $G$ memiliki suatu rainbow $u-v$ geodesic untuk setiap dua titik $u$ dan $v$ di $G$.Minimum $k$ yang terdapat pada pewarnaan $c: E(G) \rightarrow\{1,2, \cdots, k\}$ sedemikian sehingga $G$ adalah strongly rainbow connected dikatakan bilangan strong rainbow connection, $\operatorname{src}(G)$, di $G$. Jadi, $r c(G) \leq \operatorname{src}(G)$ untuk setiap graf terhubung di $G$. Pada paper ini akan diulas kembali tentang Bilangan Rainbow Connection untuk Beberapa Graf Thorn.
\end{abstract}

Kata Kunci: Bilangan Rainbow Connection, graf Thorn

\section{Pendahuluan}

Konsep rainbow connection dari suatu graf pertama kali diperkenalkan oleh Chartrand, Johns, McKeon dan Zhang [3] pada tahun 2008. Misalkan $G=(V(G), E(G))$ adalah suatu graf terhubung tak trivial. Definisi pewarnaan $c: E(G) \rightarrow$ $\{1,2, \cdots, k\}, k \in N$, dimana dua sisi yang bertetangga boleh berwarna sama. Suatu lintasan $u-v$ path $P$ di $G$ dinamakan rainbow path jika tidak terdapat dua sisi di $P$ yang berwarna sama. Graf $G$ disebut rainbow connected jika setiap dua titik yang berbeda di $G$ dihubungkan oleh rainbow path.

Pewarnaaan sisi yang menyebabkan $G$ bersifat rainbow connected dikatakan rainbow coloring. Jelas jika $G$ adalah rainbow connected, maka $G$ terhubung. Sebaliknya, setiap graf terhubung memiliki pewarnaan sisi trivial sehingga $G$ bersifat rainbow connected, yaitu setiap sisi diwarnai dengan warna berbeda. Bilangan Rainbow connection dari graf terhubung $G$, ditulis $r c(G)$, didefinisikan sebagai banyaknya warna minimal yang diperlukan untuk membuat graf $G$ bersifat rain- 
bow connected. Suatu rainbow coloring yang menggunakan sebanyak $\operatorname{rc}(G)$ warna dikatakan minimum rainbow coloring.

Misalkan $c$ adalah rainbow coloring dari graf terhubung $G$. Untuk dua titik $u$ dan $v$ di $G$, rainbow $u-v$ geodesic pada $G$ adalah rainbow $u-v$ path yang panjangnya $d(u, v)$ dimana $d(u, v)$ adalah jarak antara $u$ dan $v$ (panjang $u-v$ path terpendek di $(G)$. Graf $G$ dikatakan strongly rainbow connected jika $G$ memiliki suatu rainbow $u-v$ geodesic untuk setiap dua titik $u$ dan $v$ di $G$. Dalam kasus ini, pewarnaan $c$ dikatakan strong rainbow coloring di $G$. Minimum $k$ yang terdapat pada pewarnaan $c: E(G) \rightarrow\{1,2, \cdots, k\}$ sedemikian sehingga $G$ adalah strongly rainbow connected dikatakan bilangan strong rainbow connection atau strong rainbow connection number, $\operatorname{src}(G)$, di $G$. Suatu strong rainbow coloring di $G$ yang menggunakan $\operatorname{src}(G)$ warna dikatakan minimum strong rainbow coloring di $G$. Jadi, $r c(G) \leq \operatorname{src}(G)$ untuk setiap graf terhubung di $G$ [3]. Selanjutnya, jika $G$ adalah graf terhubung tak trivial dengan ukuran $m$ dan $\operatorname{diam}(G)=\max \{d(u, v) \mid u, v \in V(G)\}$, maka

$$
\operatorname{diam}(G) \leq \operatorname{rc}(G) \leq \operatorname{src}(G) \leq m .
$$

Pada paper ini akan dikaji tentang Bilangan Rainbow Connection untuk Beberapa Graf Thorn.

\section{Bilangan Rainbow Connection}

Berikut disajikan kembali propositionosisi yang membahas tentang graf $G$ yang mempunyai $\operatorname{rc}(G)$ dan $\operatorname{src}(G) 1,2$ dan $m$.

Proposisi 2.1. [3] Misalkan $G$ adalah suatu graf terhubung tak trivial yang berukuran m. Maka

(1) $\operatorname{rc}(G)=\operatorname{src}(G)=1$ jika dan hanya jika $G$ merupakan graf lengkap,

(2) $\operatorname{rc}(G)=2$ jika dan hanya jika $\operatorname{src}(G)=2$, dan

(3) $r c(G)=\operatorname{src}(G)=m$ jika dan hanya jika $G$ suatu graf pohon.

Proposisi 2.2. [3] Untuk setiap bilangan bulat positif $n \geq 4, \operatorname{rc}\left(C_{n}\right)=\operatorname{src}\left(C_{n}\right)=$ $\left\lceil\frac{n}{2}\right\rceil$.

Definisi 2.3. [7] Misalkan $l_{1}, l_{2}, \cdots, l_{n}$ adalah bilangan-bilangan bulat positif dan $G$ adalah suatu graf dengan $V(G)=\left\{v_{1}, v_{2}, \cdots, v_{n}\right\}$. Thorn dari graf $G$, dengan parameter $l_{1}, l_{2}, \cdots, l_{n}$ diperoleh dengan menghubungkan $l_{i}$ titik baru berderajat 1 ke titik $v_{i}$ dari graf $G(i \in 1, \cdots, n)$.

Graf thorn dari graf $G$ dinotasikan dengan $G^{*}$ atau $G^{*}\left(l_{1}, l_{2}, \cdots, l_{n}\right)$ jika masingmasing parameter ditentukan. Contoh graf thorn diperlihatkan pada Gambar 1.

Teorema berikut menyajikan bilangan rainbow connection untuk graf thorn dari graf lengkap. Pada teorema berikut akan ditinjau graf thorn untuk setiap $l_{i} \geq n$ $(i \in\{1, \cdots, n\})$

Teorema 2.4. [n] Untuk $n \geq 1$ dan $l_{i} \geq n$, berlaku

$$
r c\left(K_{n}^{*}\right)=\operatorname{src}\left(K_{n}^{*}\right)=\sum_{i=1}^{n} l_{i} .
$$




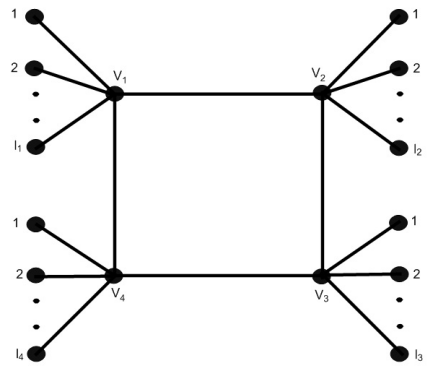

Gambar 1. Graf $C_{4}^{*}\left(l_{1}, l_{2}, \cdots, l_{4}\right)$.

Bukti. Perhatikan bahwa $u_{i j}$ adalah thorn dari titik $v_{i}(i \in\{1, \cdots, n\}, j \in$ $\left.\left\{1, \cdots, l_{i}\right\}\right)$. Perhatikan Gambar 2.

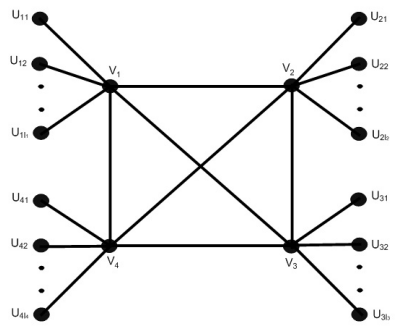

Gambar 2. Graf $K_{4}^{*}$

Terlebih dahulu akan ditunjukkan bahwa $r c\left(K_{n}^{*}\right) \leq \sum_{i=1}^{n} l_{i}$. Karena semua path dari $u_{i_{1} j_{1}}$ ke $u_{i_{2} j_{2}}$ perlu melalui sisi $u_{i_{1} j_{1}} v_{i_{1}}, v_{i_{2}} u_{i_{2} j_{2}}$, ini jelas bahwa warna dari sisi $v_{i} u_{i j}$ dimana $\left(i \in\{1, \cdots, n\}, j \in\left\{1, \cdots, l_{i}\right\}\right)$ haruslah berbeda. Dengan kata lain, ini merupakan syarat perlu untuk rainbow connectivity suatu graf. Oleh karena itu, dalam pewarnaan ini warnai semua sisi thorn $v_{i} u_{i j}$ dengan $c\left(v_{i} u_{i j}\right)=j^{(i)}$ dimana $j^{(i)}, i \in\{1, \cdots, n\}, j \in\left\{1, \cdots, l_{i}\right\}$ terlebih dahulu sebagai kode pewarnaan dari sisi graf.

Warnai sisi lain dengan cara berikut.

$$
\begin{aligned}
& c\left(v_{i} v_{j}\right)=(j+1)^{(i+1)}, \text { untuk } i<j<n, i \in\{1, \cdots, n\}, j \in\left\{1, \cdots, l_{i}\right\}, \\
& c\left(v_{i} v_{n}\right)=1^{(i+1)}, \text { untuk } i \in\{1, \cdots, n\}, \\
& c\left(v_{n} v_{1}\right)=2^{(2)} .
\end{aligned}
$$

Hal ini jelas bahwa lintasan dari $u_{i_{1} j_{1}} v_{i_{1}}-v_{i_{1}} v_{i_{2}}-v_{i_{2}} u_{i_{2} j_{2}}$ dengan pewarnaan $j_{1}^{\left(i_{1}\right)}-\left(i_{2}+1\right)^{\left(i_{1}+1\right)}-j_{2}^{\left(i_{2}\right)}$ sedangkan $u_{i_{1} j_{1}} v_{i_{1}}-v_{i_{1}} v_{n}-v_{n} u_{n j_{2}}$ dengan pewarnaan $j_{1}^{\left(i_{1}\right)}-1^{\left(i_{1}+1\right)}-j_{2}^{(n)} \cdot j_{1}^{(n)}-2^{(2)}-j_{2}^{(1)}$ adalah kode pewarnaan dari lintasan $u_{n j_{1}} v_{n}-v_{n} v_{1}-v_{1} u_{1 j_{2}}$. Semua lintasan dari graf memiliki warna yang berbeda. Dengan kata lain, setiap dua titik dari graf $K_{n}^{*}$ merupakan lintasan rainbow connected dengan $\sum_{i=1}^{n} l_{i}$ warna. Jadi, dapat dibangun sebuah rainbow $\sum_{i=1}^{n} l_{i}$-coloring 
dari $K_{n}^{*}$ sehingga dapat membuat graf $K_{n}^{*}$ rainbow connected. Ini berarti bahwa $r c\left(K_{n}^{*}\right) \leq \sum_{i=1}^{n} l_{i}$

Selanjutnya, akan ditunjukkan bahwa $r c\left(K_{n}^{*}\right) \geq \sum_{i=1}^{n} l_{i}$. Asumsikan berlawanan sehingga $r c\left(K_{n}^{*}\right) \leq \sum_{i=1}^{n} l_{i}-1$. Misalkan $c^{1}$ adalah rainbow $\sum_{i=1}^{n} l_{i}-1$-coloring dari $K_{n}^{*}$. Misalkan bahwa $u_{i_{1} j_{1}} v_{i_{1}}$ dan $v_{i_{2}} u_{i_{2} j_{2}}$ adalah dua sisi dengan warna yang sama, maka lintasan $u_{i_{1} j_{1}}-u_{i_{2} j_{2}}$ di $K_{n}^{*}$ bukanlah rainbow path. Ini menyebabkan kontradiksi, haruslah $\operatorname{rc}\left(K_{n}^{*}\right) \geq \sum_{i=1}^{n} l_{i}$, selanjutnya diperoleh bahwa $\operatorname{rc}\left(K_{n}^{*}\right)=$ $\sum_{i=1}^{n} l_{i}$.

Kemudian, akan ditunjukkan bahwa $c$ rainbow coloring adalah strong rainbow coloring. Karena $u_{i_{1} j_{1}} v_{i_{1}}-v_{i_{1}} v_{i_{2}}-v_{i_{2}} u_{i_{2} j_{2}}$ adalah lintasan dengan panjang $d\left(u_{i_{1} j_{1}}, u_{i_{2} j_{2}}\right)$ antara $u_{i_{1} j_{1}}$ dan $u_{i_{2} j_{2}}$ di $K_{n}^{*}$, dimana $i_{1}, i_{2} \in\{1, \cdots, n\}$ dan $i_{1} \neq i_{2}, j_{1} \in\left\{1, \cdots, l_{i 1}\right\}, j_{2} \in\left\{1, \cdots, l_{i 2}\right\}$, sehingga $c$ rainbow coloring dapat membuat $K_{n}^{*}$ strongly rainbow connected. Jadi diperoleh $\operatorname{src}\left(K_{n}^{*}\right) \leq \sum_{i=1}^{n} l_{i}$.

Selanjutnya, akan ditunjukkan bahwa $\operatorname{src}\left(K_{n}^{*}\right) \geq \sum_{i=1}^{n} l_{i}$. Misalkan tanpa mengurangi keumuman sehingga $\operatorname{src}\left(K_{n}^{*}\right)=\sum_{i=1}^{n} l_{i}-1$. Terdapat paling sedikit dua sisi thorn yang berwarna sama, maka rainbow geodesic dari satu thorn dengan yang lainnya tidak ada, sehingga ini kontradiksi. Oleh karena itu $\operatorname{src}\left(K_{n}^{*}\right)=\sum_{i=1}^{n} l_{i}$.

Akibatnya, karena $\operatorname{rc}\left(K_{n}^{*}\right)=\sum_{i=1}^{n} l_{i}$ dan $\operatorname{src}\left(K_{n}^{*}\right)=\sum_{i=1}^{n} l_{i}$ maka $r c\left(K_{n}^{*}\right)=$ $\operatorname{src}\left(K_{n}^{*}\right)=\sum_{i=1}^{n} l_{i}$

Berikut diberikan ilustrasi untuk graf thorn dari graf lengkap dengan $n=4$, pada Gambar 3 terlihat bahwa $r c\left(K_{4}^{*}\right)=\operatorname{src}\left(K_{4}^{*}\right)=16$.

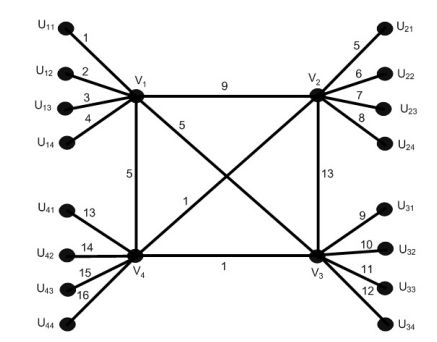

Gambar 3. $r c\left(K_{4}^{*}\right)=\operatorname{src}\left(K_{4}^{*}\right)=16$

Teorema berikut menyajikan bilangan rainbow connection untuk graf thorn dari graf lingkaran. Pada teorema berikut akan ditinjau graf thorn untuk setiap $l_{i} \geq n$ $(i \in\{1, \cdots, n\})$.

Teorema 2.5. [n] Untuk $n \geq 4$ dan $l_{i} \geq n$, berlaku

$$
r c\left(C_{n}^{*}\right)=\operatorname{src}\left(C_{n}^{*}\right)=\left\lceil\frac{n}{2}\right\rceil+\sum_{i=1}^{n} l_{i} .
$$

Bukti. Perhatikan Gambar 4.

Untuk $n \geq 4$, perhatikan bahwa lingkaran $C_{n}$ dengan $n$ titik dan untuk setiap $i$ dengan $1 \leq i \leq n$, misalkan $e_{i}=v_{i} v_{i+1}$. Misalkan $c$ sebagai sisi-coloring dari $C_{n}$ 


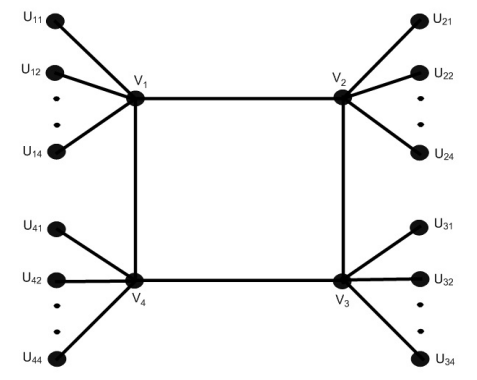

Gambar 4. Graf $C_{4}^{*}$.

sebagai berikut:

$$
c\left(e_{i}\right)= \begin{cases}i, & \text { untuk } 1 \leq i \leq\left\lceil\frac{n}{2}\right\rceil \\ i-\left\lceil\frac{n}{2}\right\rceil, & \text { untuk }\left\lceil\frac{n}{2}\right\rceil+1 \leq i \leq n\end{cases}
$$

Karena warna dari sisi thorn harus berbeda, maka berlaku bahwa $r c\left(C_{n}^{*}\right) \leq\left\lceil\frac{n}{2}\right\rceil+$ $\sum_{i=1}^{n} l_{i}$.

Selanjutnya, akan ditunjukkan bahwa $r c\left(C_{n}^{*}\right) \geq\left\lceil\frac{n}{2}\right\rceil+\sum_{i=1}^{n} l_{i}$, asumsikan berlawanan sehingga $r c\left(C_{n}^{*}\right) \leq\left\lceil\frac{n}{2}\right\rceil+\sum_{i=1}^{n} l_{i}-1$. Misalkan $c^{*}$ adalah rainbow $\left(\left\lceil\frac{n}{2}\right\rceil+\sum_{i=1}^{n} l_{i}-1\right)$-coloring dari $C_{n}^{*}$. Asumsikan bahwa $c^{*}\left(e_{i}\right)=c\left(e_{i}\right)$ maka terdapat paling sedikit dua sisi thorn dengan warna yang sama. Sebaliknya, jika $c^{*}\left(v_{i} u_{i j}\right)=c\left(v_{i} u_{i j}\right)$ maka $\left(\left\lceil\frac{n}{2}\right\rceil+\sum_{i=1}^{n} l_{i}-1\right)$-coloring dari $C_{n}^{*}$ memberikan $\left\lceil\frac{n}{2}\right\rceil-1$ warna yang berbeda sedangkan sisa $n$ sisi dari $C_{n}$ bukanlah sebuah rainbow coloring. Karena itu, nyatakan sebagai $r c\left(C_{n}^{*}\right)=\left\lceil\frac{n}{2}\right\rceil+\sum_{i=1}^{n} l_{i}$.

Selanjutnya, akan ditunjukkan bahwa $\operatorname{src}\left(C_{n}^{*}\right)=\left\lceil\frac{n}{2}\right\rceil+\sum_{i=1}^{n} l_{i}$. Karena $\operatorname{diam}\left(C_{n}\right)=\left\lceil\frac{n}{2}\right\rceil$ dan pewarnaan dari sisi thorn haruslah berbeda, maka dapat simpulkan bahwa $\operatorname{src}\left(C_{n}^{*}\right) \leq\left\lceil\frac{n}{2}\right\rceil+\sum_{i=1}^{n} l_{i}$. Selanjutnya, akan ditunjukkan bahwa $\operatorname{src}\left(C_{n}^{*}\right) \geq\left\lceil\frac{n}{2}\right\rceil+\sum_{i=1}^{n} l_{i}$. Asumsikan berlawanan sehingga $\operatorname{src}\left(C_{n}^{*}\right) \leq$ $\left\lceil\frac{n}{2}\right\rceil+\sum_{i=1}^{n} l_{i}-1$. Misalkan $c^{1}$ adalah rainbow $\left(\left\lceil\frac{n}{2}\right\rceil+\sum_{i=1}^{n} l_{i}-1\right)$-coloring dari $C_{n}^{*}$. Asumsikan bahwa $c^{1}\left(e_{i}\right)=c\left(e_{i}\right)$ maka terdapat paling sedikit dua sisi thorn dengan warna yang sama. Asumsikan bahwa $c^{1}\left(u_{i j}\right)=c\left(u_{m n}\right)(i \neq m \in\{1,2, \cdots, n\})$, maka tidak terdapat $u_{i j} v_{i}-v_{m} u_{m n}$ geodesic pada $C_{n}^{*}$. Similar untuk pembuktian dari bilangan rainbow connection, asumsikan bahwa $c^{1}\left(v_{i} u_{i j}\right)=c\left(v_{i} u_{i j}\right)$ maka ini merupakan kontradiksi dari $\operatorname{src}\left(C_{n}\right)=\left\lceil\frac{n}{2}\right\rceil$.

Akibatnya, karena $\operatorname{rc}\left(C_{n}^{*}\right)=\left\lceil\frac{n}{2}\right\rceil+\sum_{i=1}^{n} l_{i}$ dan $\operatorname{src}\left(C_{n}^{*}\right)=\left\lceil\frac{n}{2}\right\rceil+\sum_{i=1}^{n} l_{i}$ maka $\operatorname{rc}\left(C_{n}^{*}\right)=\operatorname{src}\left(C_{n}^{*}\right)=\left\lceil\frac{n}{2}\right\rceil+\sum_{i=1}^{n} l_{i}$.

Berikut diberikan ilustrasi untuk graf thorn dari graf lingkaran dengan $n=4$, pada Gambar 5 terlihat bahwa $r c\left(C_{4}^{*}\right)=\operatorname{src}\left(C_{4}^{*}\right)=18$.

Teorema berikut menyajikan bilangan rainbow connection untuk graf thorn dari graf barbel. Pada teorema berikut akan ditinjau graf thorn untuk setiap $l_{i} \geq 2 n$ $(i \in\{1, \cdots, 2 n\})$. 


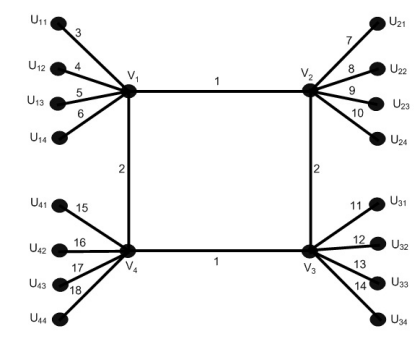

Gambar 5. Graf $C_{4}^{*}$.

Teorema 2.6. $\diamond$ Untuk $n \geq 2$ dan $l_{i} \geq 2 n$, berlaku

$$
r c\left(B_{n}^{*}\right)=\operatorname{src}\left(B_{n}^{*}\right)=3+\sum_{i=1}^{2 n} l_{i} .
$$

Bukti. Perhatikan bahwa $u_{i j}$ adalah thorn dari titik $v_{i}(i \in\{1, \cdots, 2 n\}, j \in$ $\left.\left\{1, \cdots, l_{i}\right\}\right)$. Perhatikan Gambar 6.

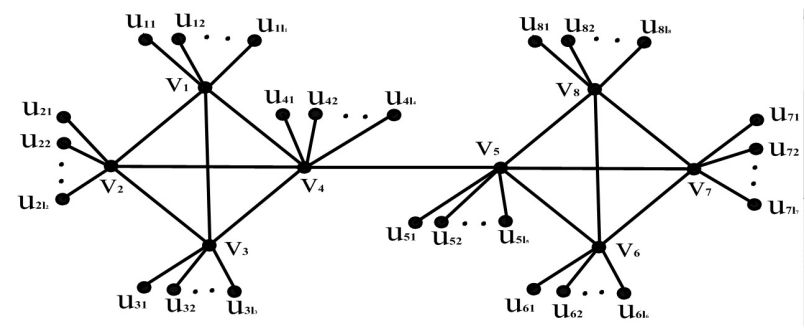

Gambar 6. Graf $B_{4}^{*}$.

Terlebih dahulu akan ditunjukkan bahwa $r c\left(B_{n}^{*}\right) \leq 3+\sum_{i=1}^{2 n} l_{i}$. Karena semua path dari $u_{i_{1} j_{1}}$ ke $u_{i_{8} j_{2}}$ perlu melalui sisi $u_{i_{1} j_{1}} v_{i_{1}}, v_{i_{8}} u_{i_{8} j_{2}}$, ini jelas bahwa warna dari sisi $v_{i} u_{i j}$ dimana $\left(i \in\{1, \cdots, 2 n\}, j \in\left\{1, \cdots, l_{i}\right\}\right)$ haruslah berbeda. Dengan kata lain, ini merupakan syarat perlu untuk rainbow connectivity suatu graf. Oleh karena itu, dalam pewarnaan ini warnai semua sisi thorn $v_{i} u_{i j}$ dengan $c\left(v_{i} u_{i j}\right)=j^{(i)}$ dimana $j^{(i)}, i \in\{1, \cdots, 2 n\}, j \in\left\{1, \cdots, l_{i}\right\}$ terlebih dahulu sebagai kode pewarnaan dari sisi graf.

Warnai sisi lain dengan cara berikut:

$$
c(e)=\left\{\begin{array}{l}
1, \text { jika } e \in\left(K_{n}^{1}\right), \\
2, \text { jika } e \in\left(K_{n}^{2}\right), \\
3, \text { jika } e \text { adalah sebuah bridge }
\end{array}\right.
$$

Hal ini jelas bahwa lintasan dari $u_{i_{1} j_{1}} v_{i_{1}}-v_{i_{1}} v_{i_{4}}-v_{i_{4}} v_{i_{5}}-v_{i_{5}} v_{i_{8}}-v_{i_{8}} u_{i_{8} j_{2}}$ dengan pewarnaan $j_{1}^{\left(i_{1}\right)}-1-3-2-j_{2}^{\left(i_{8}\right)}$ sedangkan $u_{i_{1} j_{1}} v_{i_{1}}-v_{i_{1}} v_{i_{4}}-v_{i_{4}} v_{i_{5}}-v_{i_{5}} v_{i_{6}}-v_{i_{6}} u_{i_{6} j_{8}}$ dengan pewarnaan $j_{1}^{\left(i_{1}\right)}-1-3-2-j_{8}^{\left(i_{6}\right)}$. Semua lintasan dari graf memiliki warna 
yang berbeda. Dengan kata lain, setiap dua titik dari graf $B_{n}^{*}$ merupakan lintasan rainbow connected dengan $3+\sum_{i=1}^{2 n} l_{i}$ warna. Jadi, dapat dibangun sebuah rainbow $3+\sum_{i=1}^{2 n} l_{i}$-coloring dari $B_{n}^{*}$ sehingga dapat membuat graf $B_{n}^{*}$ rainbow connected. Ini berarti bahwa $r c\left(B_{n}^{*}\right) \leq 3+\sum_{i=1}^{2 n} l_{i}$.

Selanjutnya, akan ditunjukkan bahwa $r c\left(B_{n}^{*}\right) \geq 3+\sum_{i=1}^{2 n} l_{i}$. Asumsikan berlawanan sehingga $r c\left(B_{n}^{*}\right) \leq 3+\sum_{i=1}^{2 n} l_{i}-1$. Misalkan $c^{1}$ adalah rainbow $3+\sum_{i=1}^{2 n} l_{i}-1$-coloring dari $B_{n}^{*}$. Misalkan bahwa $u_{i_{1} j_{1}} v_{i_{1}}$ dan $v_{i_{8}} u_{i_{8} j_{2}}$ adalah dua sisi dengan warna yang sama, maka lintasan $u_{i_{1} j_{1}}-u_{i_{8} j_{2}}$ di $B_{n}^{*}$ bukanlah rainbow path. Ini menyebabkan kontradiksi, sehingga haruslah $\operatorname{rc}\left(B_{n}^{*}\right) \geq 3+\sum_{i=1}^{2 n} l_{i}$ selanjutnya diperoleh bahwa $\operatorname{rc}\left(B_{n}^{*}\right)=3+\sum_{i=1}^{2 n} l_{i}$.

Kemudian, akan ditunjukkan bahwa $c$ rainbow coloring adalah strong rainbow coloring. Karena $u_{i_{1} j_{1}} v_{i_{1}}-v_{i_{1}} v_{i_{4}}-v_{i_{4}} v_{i_{5}}-v_{i_{5}} v_{i_{8}}-v_{i_{8}} u_{i_{8} j_{2}}$ adalah lintasan dengan panjang $d\left(u_{i_{1} j_{1}}, u_{i_{8} j_{2}}\right)$ antara $u_{i_{1} j_{1}}$ dan $u_{i_{8} j_{2}}$ di $B_{n}^{*}$, dimana $i_{1}, i_{4},, i_{5}, i_{8} \in$ $\{1, \cdots, 2 n\}$ dan $i_{1} \neq i_{4} \neq i_{5} \neq i_{8}, j_{1} \in\left\{1, \cdots, l_{i 1}\right\}, j_{2} \in\left\{1, \cdots, l_{i 8}\right\}$, sehingga $c$ rainbow coloring dapat membuat $B_{n}^{*}$ strongly rainbow connected. Dengan kata lain $\operatorname{src}\left(B_{n}^{*}\right) \leq 3+\sum_{i=1}^{2 n} l_{i}$.

Selanjutnya akan ditunjukkan bahwa $r c\left(B_{n}^{*}\right) \geq 3+\sum_{i=1}^{2 n} l_{i}$. Misalkan tanpa mengurangi keumuman sehingga $\operatorname{src}\left(B_{n}^{*}\right)=3+\sum_{i=1}^{2 n} l_{i}-1$. Terdapat paling sedikit dua sisi thorn yang berwarna sama, maka rainbow geodesic dari satu thorn dengan yang lainnya tidak ada, sehingga ini kontradiksi. Oleh karena itu $\operatorname{src}\left(B_{n}^{*}\right)=3+$ $\sum_{i=1}^{2 n} l_{i}$.

Akibatnya, karena $\operatorname{rc}\left(B_{n}^{*}\right)=3+\sum_{i=1}^{2 n} l_{i}$ dan $\operatorname{src}\left(B_{n}^{*}\right)=3+\sum_{i=1}^{2 n} l_{i}$ maka $r c\left(B_{n}^{*}\right)=\operatorname{src}\left(B_{n}^{*}\right)=3+\sum_{i=1}^{2 n} l_{i}$.

Berikut diberikan ilustrasi untuk graf thorn dari graf barbel dengan $n=3$, pada Gambar 7 terlihat bahwa $r c\left(B_{3}^{*}\right)=\operatorname{src}\left(B_{3}^{*}\right)=39$.

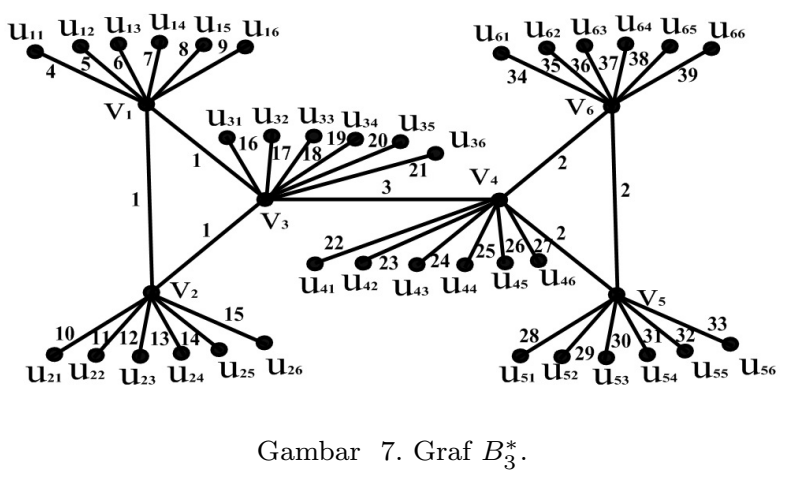

Teorema berikut menyajikan bilangan rainbow connection untuk graf thorn dari graf lolipop. Pada teorema berikut akan ditinjau graf thorn untuk setiap $l_{i} \geq n+m$ $(i \in\{1, \cdots,(n+m)\})$ 
Teorema 2.7. $\diamond$ Untuk $n \geq 1, m \geq 2$ dan $l_{i} \geq n+m$, berlaku

$$
r c\left(L_{m, n}^{*}\right)=\operatorname{src}\left(L_{m, n}^{*}\right)=(n+1)+\sum_{i=1}^{n+m} l_{i}
$$

Bukti. Perhatikan bahwa $u_{i j}$ adalah thorn dari titik $v_{i}(i \in\{1, \cdots, m\}, j \in$ $\left.\left\{1, \cdots, l_{i}\right\}\right)$ dan $w_{i j}$ adalah thorn dari sisi $x_{i}\left(i \in\{1, \cdots, n\}, j \in\left\{1, \cdots, l_{i}\right\}\right)$. Perhatikan Gambar ??.

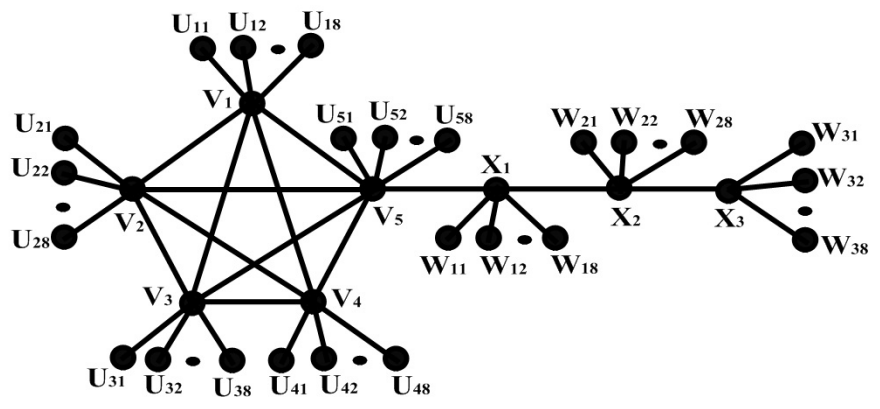

Gambar 8. Graf $L_{5,3}^{*}$.

Misalkan $v_{1}, v_{2}, \cdots, v_{m}$ adalah himpunan titik-titik dari graf lengkap $K_{m}$ dan $x_{1}, x_{2}, \cdots, x_{n}$ adalah himpunan titik-titik dari graf lintasan $P_{n}$. Misalkan titik $v_{m}$ dibuat berdekatan dengan $x_{1}$ pada graf $L_{m, n}^{*}$. Sedemikian sehingga ada tepat satu path connecting dari titik $x_{n}$ dan $v_{m}$ dengan panjang $(n-1)+1=n$.

Terlebih dahulu akan ditunjukkan bahwa $\operatorname{rc}\left(L_{m, n}^{*}\right) \leq(n+1)+\sum_{i=1}^{n+m} l_{i}$. Karena semua path dari $u_{i_{1} j_{1}}$ ke $w_{i_{3} j_{2}}$ perlu melalui sisi $u_{i_{1} j_{1}} v_{i_{1}}, x_{i_{3}} w_{i_{3} j_{2}}$, ini jelas bahwa warna dari sisi $v_{i} u_{i j}$ dimana $\left(i \in\{1, \cdots, m\}, j \in\left\{1, \cdots, l_{i}\right\}\right)$ dan sisi $x_{i} w_{i j}$ dimana $\left(i \in\{1, \cdots, n\}, j \in\left\{1, \cdots, l_{i}\right\}\right)$ haruslah berbeda. Dengan kata lain, ini merupakan syarat perlu untuk rainbow connectivity suatu graf. Oleh karena itu, dalam pewarnaan ini warnai semua sisi thorn $v_{i} u_{i j}$ dengan $c\left(v_{i} u_{i j}\right)=j^{(i)}$ dimana $j^{(i)}, i \in\{1, \cdots, m\}, j \in\left\{1, \cdots, l_{i}\right\}$ dan sisi thorn $x_{i} w_{i j}$ dengan $c\left(x_{i} w_{i j}\right)=j^{(i)}$ dimana $j^{(i)}, i \in\{1, \cdots, n\}, j \in\left\{1, \cdots, l_{i}\right\}$ terlebih dahulu sebagai kode pewarnaan dari sisi graf.

Warnai sisi lain dengan cara berikut:

$$
c(e)= \begin{cases}n-1, & \text { untuk } e \in\left(P_{n}\right), \\ n+1, & \text { untuk } e \in\left(K_{m}\right), \\ n, & \text { untuk } e \text { adalah sebuah bridge }\end{cases}
$$

Hal ini jelas bahwa lintasan dari $u_{i_{1} j_{1}} v_{i_{1}}-v_{i_{1}} v_{i_{5}}-v_{i_{5}} x_{i_{1}}-x_{i_{1}} x_{i_{2}}-x_{i_{2}} x_{i_{3}}-x_{i_{3}} w_{i_{3} j_{2}}$ dengan pewarnaan $j_{1}^{\left(i_{1}\right)}-4-3-2-1-j_{2}^{\left(i_{3}\right)}$ sedangkan $u_{i_{2} j_{1}} v_{i_{2}}-v_{i_{2}} v_{i_{5}}-v_{i_{5}} x_{i_{1}}-$ $x_{i_{1}} x_{i_{2}}-x_{i_{2}} x_{i_{3}}-x_{i_{3}} w_{i_{3} j_{3}}$ dengan pewarnaan $j_{1}^{\left(i_{2}\right)}-4-3-2-1-j_{3}^{\left(i_{3}\right)}$. Semua lintasan dari graf memiliki warna yang berbeda. Dengan kata lain, setiap dua titik dari graf $L_{m, n}^{*}$ merupakan lintasan rainbow connected dengan $(n+1)+\sum_{i=1}^{n+m} l_{i}$ 
warna. Jadi, dapat dibangun sebuah rainbow $(n+1)+\sum_{i=1}^{n+m} l_{i}$-coloring dari $L_{m, n}^{*}$ sehingga dapat membuat graf $L_{m, n}^{*}$ rainbow connected. Ini berarti bahwa $\operatorname{rc}\left(L_{m, n}^{*}\right) \leq$ $(n+1)+\sum_{i=1}^{n+m} l_{i}$.

Selanjutnya, akan ditunjukkan bahwa $\operatorname{rc}\left(L_{m, n}^{*}\right) \geq(n+1)+\sum_{i=1}^{n+m} l_{i}$. Asumsikan berlawanan sehingga $r c\left(L_{m, n}^{*}\right) \leq(n+1)+\sum_{i=1}^{n+m} l_{i}-1$. Misalkan $c^{1}$ adalah rainbow $(n+1)+\sum_{i=1}^{n+m} l_{i}-1$-coloring dari $L_{m, n}^{*}$. Misalkan bahwa $u_{i_{1} j_{1}} v_{i_{1}}$ dan $x_{i_{3}} w_{i_{3} j_{2}}$ adalah dua sisi dengan warna yang sama, maka lintasan $u_{i_{1} j_{1}}-w_{i_{3} j_{2}}$ di $L_{m, n}^{*}$ bukanlah rainbow path. Ini menyebabkan kontradiksi, sehingga haruslah $\operatorname{rc}\left(L_{m, n}^{*}\right) \geq$ $(n+1)+\sum_{i=1}^{n+m} l_{i}$, selanjutnya diperoleh bahwa $r c\left(L_{m, n}^{*}\right)=(n+1)+\sum_{i=1}^{n+m} l_{i}$.

Kemudian, akan ditunjukkan bahwa $c$ rainbow coloring adalah strong rainbow coloring. Karena $u_{i_{1} j_{1}} v_{i_{1}}-v_{i_{1}} v_{i_{5}}-v_{i_{5}} x_{i_{1}}-x_{i_{1}} x_{i_{2}}-x_{i_{2}} x_{i_{3}}-x_{i_{3}} w_{i_{3} j_{2}}$ adalah lintasan dengan panjang $d\left(u_{i_{1} j_{1}}, w_{i_{3} j_{2}}\right)$ antara $u_{i_{1} j_{1}}$ dan $w_{i_{3} j_{2}}$ di $L_{m, n}^{*}$, dimana $i_{1}, i_{5} \in\{1, \cdots, m\}$ dan $i_{1} \neq i_{5}, i_{1}, i_{2}, i_{3} \in\{1, \cdots, n\}$ dan $i_{1} \neq i_{2} \neq i_{3}$, $j_{1} \in\left\{1, \cdots, l_{i 1}\right\}, j_{2} \in\left\{1, \cdots, l_{i 3}\right\}$, sehingga $c$ rainbow coloring dapat membuat $L_{m, n}^{*}$ strongly rainbow connected. Dengan kata lain $\operatorname{src}\left(L_{m, n}^{*}\right) \leq(n+1)+\sum_{i=1}^{n+m} l_{i}$.

Selanjutnya akan ditunjukkan bahwa $\operatorname{src}\left(L_{m, n}^{*}\right) \geq(n+1)+\sum_{i=1}^{n+m} l_{i}$. Misalkan tanpa mengurangi keumuman sehingga $\operatorname{src}\left(L_{m, n}^{*}\right)=(n+1)+\sum_{i=1}^{n+m} l_{i}-1$. Terdapat paling sedikit dua sisi thorn yang berwarna sama, maka rainbow geodesic dari satu thorn dengan yang lainnya tidak ada, sehingga ini kontradiksi. Oleh karena itu $\operatorname{src}\left(L_{m, n}^{*}\right)=(n+1)+\sum_{i=1}^{n+m} l_{i}$.

Akibatnya, karena $\operatorname{rc}\left(L_{m, n}^{*}\right)=(n+1)+\sum_{i=1}^{n+m} l_{i}$ dan $\operatorname{src}\left(L_{m, n}^{*}\right)=(n+1)+$ $\sum_{i=1}^{n+m} l_{i}$ maka $\operatorname{rc}\left(L_{m, n}^{*}\right)=\operatorname{src}\left(L_{m, n}^{*}\right)=(n+1)+\sum_{i=1}^{n+m} l_{i}$.

Berikut diberikan ilustrasi untuk graf thorn dari graf lolipop dengan $m=3, n=$ 2 , pada Gambar 9 terlihat bahwa $r c\left(L_{3,2}^{*}\right)=\operatorname{src}\left(L_{3,2}^{*}\right)=28$.

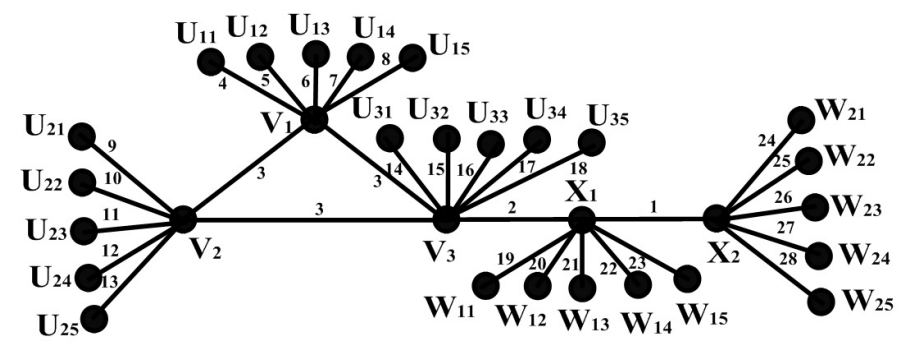

Gambar 9. Graf $L_{3,2}^{*}$

Teorema berikut menyajikan bilangan rainbow connection untuk graf thorn dari graf tadpole. Pada teorema berikut akan ditinjau graf thorn untuk setiap $l_{i} \geq n+m$ $(i \in\{1, \cdots,(n+m)\})$. 
Teorema 2.8. $\diamond$ Untuk $n \geq 1, m \geq 3$ dan $l_{i} \geq n+m$, berlaku

$$
r c\left(T_{m, n}^{*}\right)=\operatorname{src}\left(T_{m, n}^{*}\right)=\left\lceil\frac{m}{2}\right\rceil+n+\sum_{i=1}^{n+m} l_{i}
$$

Bukti. Perhatikan bahwa $u_{i j}$ adalah thorn dari titik $v_{i}(i \in\{1, \cdots, m\}, j \in$ $\left.\left\{1, \cdots, l_{i}\right\}\right)$ dan $w_{i j}$ adalah thorn dari sisi $x_{i}\left(i \in\{1, \cdots, n\}, j \in\left\{1, \cdots, l_{i}\right\}\right)$. Perhatikan Gambar 10.

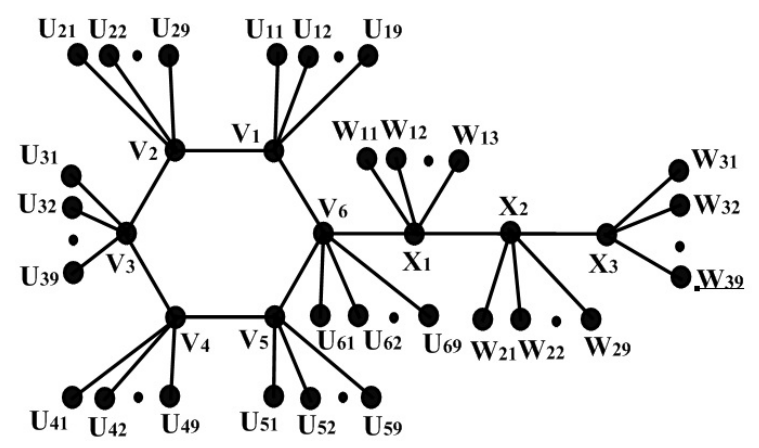

Gambar 10. Graf $T_{6,3}^{*}$

Misalkan $v_{1}, v_{2}, \cdots, v_{m}$ adalah himpunan titik-titik dari graf lingkaran $C_{m}$ dan $x_{1}, x_{2}, \cdots, x_{n}$ adalah himpunan titik-titik dari graf lintasan $P_{n}$. Misalkan titik $v_{m}$ dibuat berdekatan dengan $x_{1}$ pada graf $T_{m, n}^{*}$. Maka $x_{1}-x_{2}-\cdots-x_{n}-v_{m}$ adalah path dengan panjang $n$ pada graf $T_{m, n}^{*}$. Sedemikian sehingga ada tepat satu path antara $v_{m}$ dan $x_{1}$.

Terlebih dahulu akan ditunjukkan bahwa $\operatorname{rc}\left(T_{m, n}^{*}\right) \leq\left\lceil\frac{m}{2}\right\rceil+n+\sum_{i=1}^{n+m} l_{i}$. Karena semua path dari $u_{i_{3} j_{1}}$ ke $w_{i_{3} j_{2}}$ perlu melalui sisi $u_{i_{3} j_{1}} v_{i_{3}}, x_{i_{3}} w_{i_{3} j_{2}}$, ini jelas bahwa warna dari sisi $v_{i} u_{i j}$ dimana $\left(i \in\{1, \cdots, m\}, j \in\left\{1, \cdots, l_{i}\right\}\right)$ dan sisi $x_{i} w_{i j}$ dimana $\left(i \in\{1, \cdots, n\}, j \in\left\{1, \cdots, l_{i}\right\}\right)$ haruslah berbeda. Dengan kata lain, ini merupakan syarat perlu untuk rainbow connectivity suatu graf. Oleh karena itu, dalam pewarnaan ini warnai semua sisi thorn $v_{i} u_{i j}$ dengan $c\left(v_{i} u_{i j}\right)=j^{(i)}$ dimana $j^{(i)}, i \in\{1, \cdots, m\}, j \in\left\{1, \cdots, l_{i}\right\}$ dan sisi thorn $x_{i} w_{i j}$ dengan $c\left(x_{i} w_{i j}\right)=j^{(i)}$ dimana $j^{(i)}, i \in\{1, \cdots, n\}, j \in\left\{1, \cdots, l_{i}\right\}$ terlebih dahulu sebagai kode pewarnaan dari sisi graf.

Warnai sisi lain dengan cara berikut:

$$
c(e)= \begin{cases}n-1, & \text { untuk } e \in\left(P_{n}\right), \\ n, & \text { untuk } e \text { adalah sebuah bridge }\end{cases}
$$

Warnai path $v_{m}-v_{1}-v_{2}-\cdots-v_{\left\lceil\frac{m}{2}\right\rceil}$ dengan pewarnaan $n+1, n+2, \cdots, n+\left\lceil\frac{m}{2}\right\rceil$ dan warnai sisi path $v_{m}-v_{m-1}-v_{m-2}-\cdots-v_{\left\lceil\frac{m}{2}\right\rceil}$ dengan pewarnaan $n+\left\lceil\frac{m}{2}\right\rceil, n+$ $\left\lceil\frac{m}{2}\right\rceil-1, \cdots, n+2, n+1$ 
Hal ini jelas bahwa lintasan dari $u_{i_{3} j_{1}} v_{i_{3}}-v_{i_{3}} v_{i_{2}}-v_{i_{2}} v_{i_{1}}-v_{i_{1}} v_{i_{6}}-v_{i_{6}} x_{i_{1}}-$ $x_{i_{1}} x_{i_{2}}-x_{i_{2}} x_{i_{3}}-x_{i_{3}} w_{i_{3} j_{2}}$ dengan pewarnaan $j_{1}^{\left(i_{3}\right)}-6-5-4-3-2-1-j_{2}^{\left(i_{3}\right)}$ sedangkan $u_{i_{3} j_{2}} v_{i_{3}}-v_{i_{3}} v_{i_{4}}-v_{i_{4}} v_{i_{5}}-v_{i_{5}} v_{i_{6}}-v_{i_{6}} x_{i_{1}}-x_{i_{1}} x_{i_{2}}-x_{i_{2}} x_{i_{3}}-x_{i_{3}} w_{i_{3} j_{1}}$ dengan pewarnaan $j_{2}^{\left(i_{3}\right)}-4-5-6-3-2-1-j_{1}^{\left(i_{3}\right)}$. Semua lintasan dari graf memiliki warna yang berbeda. Dengan kata lain, setiap dua titik dari graf $T_{m, n}^{*}$ merupakan lintasan rainbow connected dengan $\left\lceil\frac{m}{2}\right\rceil+n+\sum_{i=1}^{n+m} l_{i}$ warna. Jadi, dapat dibangun sebuah rainbow $\left\lceil\frac{m}{2}\right\rceil+n+\sum_{i=1}^{n+m} l_{i}$-coloring dari $T_{m, n}^{*}$ sehingga dapat membuat graf $T_{m, n}^{*}$ rainbow connected. Ini berarti bahwa $\operatorname{rc}\left(T_{m, n}^{*}\right) \leq\left\lceil\frac{m}{2}\right\rceil+n+\sum_{i=1}^{n+m} l_{i}$.

Selanjutnya, akan ditunjukkan bahwa $r c\left(T_{m, n}^{*}\right) \geq\left\lceil\frac{m}{2}\right\rceil+n+\sum_{i=1}^{n+m} l_{i}$. Asumsikan berlawanan sehingga $r c\left(T_{m, n}^{*}\right) \leq\left\lceil\frac{m}{2}\right\rceil+n+\sum_{i=1}^{n+m} l_{i}-1$. Misalkan $c^{1}$ adalah rainbow $\left\lceil\frac{m}{2}\right\rceil+n+\sum_{i=1}^{n+m} l_{i}-1$-coloring dari $T_{m, n}^{*}$. Misalkan bahwa $u_{i_{3} j_{1}} v_{i_{3}}$ dan $x_{i_{3}} w_{i_{3} j_{2}}$ adalah dua sisi dengan warna yang sama, maka lintasan $u_{i_{3} j_{1}}-w_{i_{3} j_{2}}$ di $T_{m, n}^{*}$ bukanlah rainbow path. Ini menyebabkan kontradiksi, sehingga haruslah $\operatorname{rc}\left(T_{m, n}^{*}\right) \geq$ $\left\lceil\frac{m}{2}\right\rceil+n+\sum_{i=1}^{n+m} l_{i}$, selanjutnya diperoleh bahwa $\operatorname{rc}\left(T_{m, n}^{*}\right)=\left\lceil\frac{m}{2}\right\rceil+n+\sum_{i=1}^{n+m} l_{i}$.

Kemudian, akan ditunjukkan bahwa $c$ rainbow coloring adalah strong rainbow coloring. Karena $u_{i_{3} j_{1}} v_{i_{3}}-v_{i_{3}} v_{i_{2}}-v_{i_{2}} v_{i_{1}}-v_{i_{1}} v_{i_{6}}-v_{i_{6}} x_{i_{1}}-x_{i_{1}} x_{i_{2}}-x_{i_{2}} x_{i_{3}}-x_{i_{3}} w_{i_{3} j_{2}}$ adalah lintasan dengan panjang $d\left(u_{i_{3} j_{1}}, w_{i_{3} j_{2}}\right)$ antara $u_{i_{3} j_{1}}$ dan $w_{i_{3} j_{2}}$ di $T_{m, n}^{*}$, dimana $i_{1}, i_{2}, i_{3}, i_{6} \in\{1, \cdots, m\}$ dan $i_{1} \neq i_{2} \neq i_{3} \neq i_{6}, i_{1}, i_{2}, i_{4} \in\{1, \cdots, n\}$ dan $i_{1} \neq i_{2} \neq i_{3}, j_{1} \in\left\{1, \cdots, l_{i 3}\right\}, j_{2} \in\left\{1, \cdots, l_{i 3}\right\}$, sehingga $c$ rainbow coloring dapat membuat $T_{m, n}^{*}$ strongly rainbow connected. Dengan kata lain $\operatorname{src}\left(T_{m, n}^{*}\right) \leq$ $\left\lceil\frac{m}{2}\right\rceil+n+\sum_{i=1}^{n+m} l_{i}$.

Selanjutnya akan ditunjukkan bahwa $\operatorname{src}\left(T_{m, n}^{*}\right)>\left\lceil\frac{m}{2}\right\rceil+n+\sum_{i=1}^{n+m} l_{i}$. Misalkan tanpa mengurangi keumuman sehingga $\operatorname{src}\left(T_{m, n}^{*}\right)=\left\lceil\frac{m}{2}\right\rceil+n+\sum_{i=1}^{n+m} l_{i}-1$. Terdapat paling sedikit dua sisi thorn yang berwarna sama, maka rainbow geodesic dari satu thorn dengan yang lainnya tidak ada, sehingga ini kontradiksi. Oleh karena itu $\operatorname{src}\left(T_{m, n}^{*}\right)=\left\lceil\frac{m}{2}\right\rceil+n+\sum_{i=1}^{n+m} l_{i}$.

Akibatnya, karena $\operatorname{rc}\left(T_{m, n}^{*}\right)=\left\lceil\frac{m}{2}\right\rceil+n+\sum_{i=1}^{n+m} l_{i}$ dan $\operatorname{src}\left(T_{m, n}^{*}\right)=\left\lceil\frac{m}{2}\right\rceil+n+$ $\sum_{i=1}^{n+m} l_{i}$ maka $r c\left(T_{m, n}^{*}\right)=\operatorname{src}\left(T_{m, n}^{*}\right)=\left\lceil\frac{m}{2}\right\rceil+n+\sum_{i=1}^{n+m} l_{i}$.

Berikut diberikan ilustrasi untuk graf thorn dari graf tadpole dengan $m=3, n=$ 2, pada Gambar 11 terlihat bahwa $\operatorname{rc}\left(T_{3,2}^{*}\right)=\operatorname{src}\left(T_{3,2}^{*}\right)=28$.

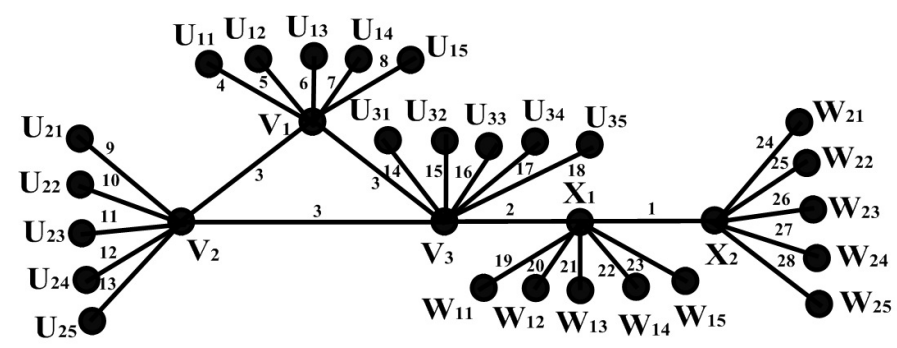

Gambar 11. Graf $T_{3,2}^{*}$ 


\section{Kesimpulan}

Pada tulisan ini telah diperoleh bilangan rainbow connection untuk graf thorn dari graf lengkap dan graf lingkaran. Selanjutnya diperoleh bilangan rainbow connection untuk graf thorn dari graf barbel, graf lolipop, dan graf tadpole.

\section{Ucapan Terima Kasih}

Penulis mengucapkan terima kasih kepada Bapak Prof. Dr. Syafrizal Sy, Bapak Dr. Muhafzan yang telah memberikan masukan dan saran, sehingga tulisan ini dapat diselesaikan dengan baik. Penulis juga mengucapkan terima kasih kepada Ibu Dr. Lyra Yulianti, Bapak Dr. Admi Nazra, Bapak Dr. Jenizon sehingga paper ini dapat dipublikasikan.

\section{Daftar Pustaka}

[1] Bondy, J.A. dan U.S.R. Murty. 2008. Graph Theory. Graduated Texts In Mathematics. Springer. New York.

[2] Chartrand, G. dan P. Zhang, 2005. Introduction to Graph Theory, McGraw-Hill International Editions, Singapore.

[3] Chartrand, G. dkk, 2008. Rainbow Connection in Graphs, Math. Bohem. 133: $85-98$.

[4] Diestel, R. 2005. Graph Theory. Electronic Edition 3. New York.

[5] Ericksen, A. 2007. Graduating Engineer 83 Computer Careers. A Matter of security, 24-28.

[6] Li, X. dan Y. Sun. 2012. Rainbow Connections of Graphs. Springer Briefs in Mathematics. Springer. New York.

[7] Liu, Y. dan Z. Wang. 2014. Rainbow Connection Number of the Thorn Graphs. Applied Mathematical Sciences 8: 6373 - 6377. 